\title{
Democracia e meio ambiente: um estudo bibliométrico da produção científica
}

Democracy and the environment: a bibliometric study of scientific production

\section{Democracia y medio ambiente: un estudio bibliométrico de la producción científica}

Recebido: 07/05/2020 | Revisado: 08/05/2020 | Aceito: 16/05/2020 | Publicado: 19/05/2020

\section{Lucas Andrade de Morais}

ORCID: https://orcid.org/0000-0003-4443-2393 Universidade do Estado do Rio Grande do Norte, Brasil E-mail: lucasmorais7@gmail.com

Lucia Santana de Freitas ORCID: https://orcid.org/0000-0001-8185-0151 Universidade Federal de Campina Grande, Brasil E-mail: lucia.sdefreitas@gmail.com

\section{Resumo}

Os impactos ambientais negativos decorrentes das diferentes atividades humanas, especialmente as organizacionais de cunho econômico, têm levado diferentes esferas como Estado, iniciativa privada e sociedade civil a buscarem conjuntamente soluções aos problemas ambientais e redução de seus reflexos no tecido social, bem como, o entendimento que tais soluções podem estar relacionadas com a democracia. Assim sendo, esses fatores têm despertado o interesse da academia em contribuir para o amadurecimento da discussão sobre a relação democracia e meio ambiente. Este estudo tem como objetivo realizar um estudo bibliométrico da produção científica que trata da relação entre meio ambiente e democracia, que vem sendo produzido na literatura pelos termos: democracia verde, ecológica, sustentável e democracia ambiental. Para tanto, o percurso metodológico adotado foi o procedimento bibliométrico no mapeamento das produções publicadas, entre 1944 e 2019, nas bases de dados internacionais Scopus e Web of Science, e contou com apoio do software VOSviewer ${ }^{\circledR}$ versão 1.6.11 e da análise interpretativa, para fazer a análise dos 118 artigos considerados. Deste modo, constatou-se que as principais redes de publicações estão centradas nos países: Estados Unidos, Reino Unido e Austrália, É válido ressaltar que as publicações são dispersas entre instituições de pesquisas, periódicos ou área de conhecimento; Os nove clusters 
identificados contemplam 18 autores com no mínimo 29 citações, cada cluster apresentam um reduzido número de trabalhos e de autores e não mantém vinculações entre si, o que resulta numa dispersão relativamente alta das publicações, entretanto, pode-se perceber um ponto em comum: a participação, mesmo que abordada em diferentes formas.

Palavras-chave: Democracia verde; Democracia ecológica; Democracia sustentável; Democracia ambiental; Bibliométrica.

\begin{abstract}
The negative environmental impacts resulting from different human activities, especially those of an economic nature, have led different spheres such as the State, private initiative and civil society to jointly seek solutions to environmental problems and reduce their impact on the social fabric, as well as the understanding that such solutions may be related to democracy. Thus, these factors have aroused the interest of the academy in contributing to the maturing of the discussion on the relationship between democracy and the environment. This study aims to conduct a bibliometric study of scientific production that deals with the relationship between the environment and democracy, which has been produced in the literature by the terms: green democracy, ecological, sustainable and environmental democracy. For this purpose, the methodological path adopted was the bibliometric procedure in the mapping of the productions published, between 1944 and 2019, in the international databases Scopus and Web of Science, and counted on the support of the software VOSviewer® version 1.6.11 and the interpretative analysis, to make the analysis of the 118 articles considered. The nine clusters identified include 18 authors with at least 29 citations, each cluster presents a small number of papers and authors and does not maintain links between them, which results in a relatively high dispersion of publications, however, one point in common can be noted: participation, even if approached in different ways.
\end{abstract}

Keywords: Green democracy; Ecological democracy; Sustainable democracy; Environmental democracy; Bibliometrics.

\title{
Resumen
}

Los impactos ambientales negativos resultantes de las diferentes actividades humanas, especialmente las de carácter económico, han llevado a diferentes esferas como el Estado, la iniciativa privada y la sociedad civil a buscar conjuntamente soluciones a los problemas ambientales y a reducir su impacto en el tejido social, así como a entender que esas soluciones pueden estar relacionadas con la democracia. Así pues, estos factores han despertado el 
interés de la academia por contribuir a la maduración del debate sobre la relación entre la democracia y el medio ambiente. El objetivo de este estudio es realizar un estudio bibliométrico de la producción científica que trata de la relación entre el medio ambiente y la democracia, que se ha producido en la literatura con los términos: democracia verde, ecológica, sostenible y ambiental. Para ello, el camino metodológico adoptado fue el procedimiento bibliométrico en la cartografía de las producciones publicadas, entre 1944 y 2019, en las bases de datos internacionales Scopus y Web of Science, y contó con el apoyo del software VOSviewer® versión 1.6.11 y el análisis interpretativo, para realizar el análisis de los 118 artículos considerados. Las nueve agrupaciones identificadas incluyen 18 autores con al menos 29 citas, cada agrupación presenta un número reducido de trabajos y autores y no mantiene vínculos entre ellos, lo que da lugar a una dispersión relativamente alta de las publicaciones; sin embargo, cabe señalar un punto en común: la participación, aunque se aborde de manera diferente.

Palabras clave: Democracia verde; Democracia ecológica; Democracia sostenible; Democracia ambiental; Bibliometría.

\section{Introdução}

A possibilidade de um colapso ambiental (Marques, 2018) decorrentes das ações antrópicas que buscam os recursos naturais para darem suporte à expansão do capitalismo vai de encontro com os limites do planeta, resultando em problemas de suporte ao vetor expansivo desse sistema, consequentemente levando ao agravamento da crise/degradação ambiental.

A diminuição das coberturas vegetais nativas, o declínio dos recursos hídricos, a degradação e desertificação dos solos, a poluição nos processos de extração e transporte de combustíveis fósseis, as mudanças climáticas, aquecimento global, o buraco na camada de ozônio e o agravamento da pressão demográfica, segundo Marques (2018), são os principais problemas ambientais que a humanidade tem enfrentado, e os fatores para se explicar essa degradação são inúmeros e complexos, incluindo os fatores econômicos, sociais, culturais e políticos.

O enfrentamento dos impactos ambientais negativos e suas consequências econômicas e sociais, tem levado os Estado-nações a buscarem soluções dos problemas gerados pela crise planetária, criando espaços de debates e construção de acordos por meio de fóruns mundiais, conferências e ações de órgãos internacionais (Barros-Platiau, Varella\& Schleicher, 2004; 
Nascimento, 2012; Bursztyn e Bursztyn, 2013; Pott \& Estrela, 2017). Nesse contexto, é relevante compreender como são construídos os processos decisórios, agendas e políticas públicas de Estado ou de governo no que diz respeito à dimensão ambiental, e se essa tensão/conflito tem sido orientada por princípios democráticos visando o equilíbrio das dimensões ambiental, econômica e social.

Na perspectiva de Acselrad et. al. (2012) o enfrentamento político da questão ambiental tem produzido a desigualdade, visto que os impactos da ação antrópica ao ambiente são distribuídos desigualmente sobre a sociedade, obrigando os mais pobres a assumirem custos e impactos mais altos das consequências negativas da crise ambiental. Portanto, o enfrentamento dos problemas ambientais está intimamente relacionado à agenda política e econômica. Sobre esse aspecto Baquero (2008) aponta a existência de sistemas híbridos que oscilam em um continuum entre democracia e autoritarismo, oportunizando às elites a apropriarem-se de fundos públicos e aumento do poder político e econômico.

Além do Estado, outro ator que assumiu relevância na proteção ambiental é a sociedade civil, seja de forma institucionalizada em redes de organizações, associações, ONG's, etc., ou pelos movimentos sociais, Ciberativismo (Carty \& Onyett, 2006; Queiroz, 2017; Mentes, 2019) e o ativismo ambiental (Dryzek, 1995; Acselrad, 2010; Armiero e D'Alisa, 2012; Gaard, 2001) e de forma não institucionalizadas.

Nesse sentido, a participação social, popular ou cidadã pode ocorrer em debates e discussões no espaço público e pode ser levada a espaços habilitados (Dryzek e Steverson, 2011), com a formação de parcerias entre as esferas públicas (sociedade civil), privadas e/ou estado pela institucionalização de Conselhos de controle, Comitês, Conferências, Ouvidorias, Mesa de Diálogo, Audiência Pública, Fórum interconselhos, Consulta Pública e etc., se constituem como espaços democráticos de participações e de interlocuções entre o Estado e a sociedade na garantia e exercício de direitos (Morais, 2017).

Ainda que tais acenos de participação e mobilização social sejam visíveis, existe entre sociedade e mercado uma assimetria de informação e de acesso ao poder econômico. A sociedade não detém o controle sobre os fluxos e locais de investimentos ficando tal decisão a cargo dos detentores do capital. São as grandes corporações que decidem quanto de recursos serão utilizados nas diferentes atividades econômicas, bem como na exploração e conservação ambiental.

Portanto, a questão ambiental é permeada por diferentes esferas. A esfera privada, incluída nos debates ambientais por serem os principais atores econômicos e agentes causadores dos impactos ambientais, bem como os demais tipos de organizações; a esfera 
social, como sujeito passivo e receptáculo das externalidades negativas organizacionais, e, como sujeitos ativos quando participam de forma ativa, individualmente ou coletivamente, na construção, implementação e fiscalização de uma agenda ambiental capaz de preservar o planeta, e, pela esfera política quando o Estado nos seus diferentes níveis de atuação, a partir do sistema de governo vigente estabelece políticas de proteção ambiental com ampla participação de atuação da sociedade e da esfera econômica.

Diante desse contexto, faz-se necessário um maior entendimento e aprofundamento da relação entre meio ambiente e democracia e uma reflexão sobre os regimes de governo para além dos sistemas de participações político-eleitorais onde possa ser incorporada com igual importância a dimensão ambiental.

Por outra parte, a relação entre meio ambiente e democracia tem despertado o interesse acadêmico para o amadurecimento da multidimensionalidade desta discussão. Tal relação vem sendo abordada na literatura por uma variedade de termos ou denominações, tais como: democracia verde (Dryzek, 1995; Arias-Maldonado, 2000, 2007); democracia ecológica (Dryzek, 1995; Gaard, 2001; Kothari, 2009, 2014ab; Dryzek \& Stevenson, 2011; Armiero e D'Alisa, 2012; Kothari, Demaria e Acosta, 2014); democracia sustentável (Bangura, 1992; Hauser, 1999; Burnell, 2001) e democracia ambiental (Lawrence, Paudel, Barnes e Malla, 2006; Tadaki, Sinner \& Chan, 2017). Essa variedade de denominações indica uma literatura em construção e que não existe um consenso em seu conceito ou denominação.

Pickering, Bäckstrand e Schlosberg (2020) ao estudar o nexo democracia-ambiente, defende que as produções científicas, especialmente em autores como Dryzek $(1995,2011)$, Eckersley (2006, 2019); Arias-Maldonado (2000) e outros, envolvendo a democracia e os resultados ambientais, têm início com os movimentos sociais ambientalistas, e seguem com as discussões políticas nos cenários locais e internacionais, apresentando teorias como a da política verde/ambiental, racionalidade ecológica, democracia deliberativa e ambientalismo, cidadania ecológica/ambiental, estado verde e mais recente a do ecofeminismo (Gaard, 2001). Essas teorias de relação democracia e meio ambiente tem como ponto em comum entender como os processos democráticos podem contribuir com desempenhos ambientais que equilibrem a relação ambiente e sociedade.

Diante do exposto e considerando a relevância do papel da academia e suas contribuições para o entendimento das complexidades que envolve a relação entre meio ambiente e democracia, o presente estudo tem como objetivo realizar um estudo bibliométrico da produção científica que trata da relação entre meio ambiente e democracia publicada durante o período de 1944 a 2019. 


\section{Metodologia}

Para conseguir identificar a natureza e os padrões de mudanças nas produções científicas foi adotado o tipo de pesquisa qualitativa pela possibilidade de interpretação subjetiva dos dados. O procedimento técnico, por sua vez, foi o do estudo bibliométrico, por fazer um levantamento de produções em bases de dados com avaliação blind review de pares.

A bibliometria surgiu na área da Ciências da Informação, apresentando como subcampos os estudos bibliométricos, cienciométricos, informétricos e webmétricos, que diferenciam-se no objeto de estudo e nos métodos e variáveis observáreis (Vanti, 2002; Espinosa et. al., 2020).

A análise bibliométrica se constituiu como um procedimento metodológico para se avaliar a produção existente entre livros, documentos e periódicos científicos, que pela geração de índices, seria possível avaliar as produções, recorrência e citações científicas das pesquisas de um país, das instituições e dos cientistas (Teixeira, Iwamoto \& Medeiros, 2013).

Esse procedimento, na literatura, tem apresentado uma estruturação em etapas básicas, que tem recebido a análise crítica de Mattos (2004) quanto à chamada contribuição para o desenvolvimento do conhecimento, no que concerne à estruturação das escolhas de categorias para construção dos bancos de dados, nos cuidados interpretativos das ambiguidades dos significados das análises básicas da bibliometria e na maneira de olhar os números apresentados pela base de dados e/ou pelo software de testes de análise estatística.

A bibliometria possibilitou mapear os autores com maior relevância em termos de citações, identificar a localização das produções científicas, o que ajudou a encontrar a existência de possíveis núcleos de estudos sobre o tema, e permitiu entender os conceitos que estão sendo utilizados, as teorias mais usuais e os métodos de pesquisas adotados, sendo possível estabelecer caminhos para diminuir as limitações das discussões.

Essa pesquisa utilizou-se da sistematização de Marconi e Lakatos (2017) quanto à formulação do desenho da pesquisa, com: 1) escolha do tema relação democracia e meio ambiente, pela multiplicidade de nomenclaturas usadas para explicar essa relação; 2) identificação da pesquisa pela seleção dos termos de buscas environmental democracy, ecological democracy, green democracy e sustainable democracy; 3) localização dos bancos de dados para se buscar artigos em jornais/revistas acadêmicas, foram, então, escolhidas Web of Science- WoS (da Clarivate Analytics) e Scopus ${ }^{\circledR}$ (da Elsevier) por se constituírem como os maiores bancos de dados de resumos e citações da literatura com revisão por pares de várias áreas do conhecimento; 4) produção de arquivo (.txt) com a base de dados das duas 
(CC BY 4.0) | ISSN 2525-3409 | DOI: http://dx.doi.org/10.33448/rsd-v9i7.4311

plataformas; 5) compilação das bibliografias encontradas; 6) escolha e utilização do softwareVOSviewer ${ }^{\circledR}$ versão 1.6.115 para criar mapas e grafo; 7) fichamento do conteúdo das bibliografias com autores, anos, objetos de estudo, perspectivas teóricas, metodologia adotada e resultados encontrados; 8) leitura e análise interpretativa dos artigos; 9) redação descritivatextual dos achados.

Os bancos de dados utilizados foram Web of Science e Scopus®. Utilizou-se como critério de inclusão (refinado) apenas artigos de avaliação blind review por pares (peer review), em qualquer idioma, das áreas das ciências sociais, humanas e as ligadas às ciências ambientais (Social Sciences; Environmental Science; Arts and Humanities; Business, Management and Accounting; Energy; Economics, Econometrics and Finance; Engineering; Decision Sciences; e Earth and Planetary Sciences), publicados entre os anos de 1944 (ano limite de busca das bases) a 2019 (a data limite de encerramento de busca foi de 03 de dezembro de 2019).

Os descritores (termos) de busca selecionados na investigação, nas duas bases, são environmental democracy or ecological democracy or green democracy or sustainable democracy, inseridos na aba de busca por artigos que apresentassem nos títulos, resumos (abstract) ou palavras-chave uma ou mais desses descritores.

A coleta da pesquisa resultou em um total de 169 artigos, distribuídos em 118 artigos científicos em periódicos na base Scopus e 51 artigos científicos em periódicos na base Web of Science. Foi feito um cruzamento dos artigos das duas bases e foi detectada a repetição de 38 artigos nas duas bases.

Considerando que mais de $70 \%$ dos artigos da base da WoS estarem contidos na Scopus, optou-se por adotar apenas os dados da Scopus por apresentar maior quantidade, viabilidade de análise em software e maior aderência ao escopo central da pesquisa.

A Figura 1 apresenta o delineamento tomado para construir a amostra do estudo: 
Research, Society and Development, v. 9, n. 7, e364974311, 2020

(CC BY 4.0) | ISSN 2525-3409 | DOI: http://dx.doi.org/10.33448/rsd-v9i7.4311

Figura 1. Delineamento para busca e análise das produções.

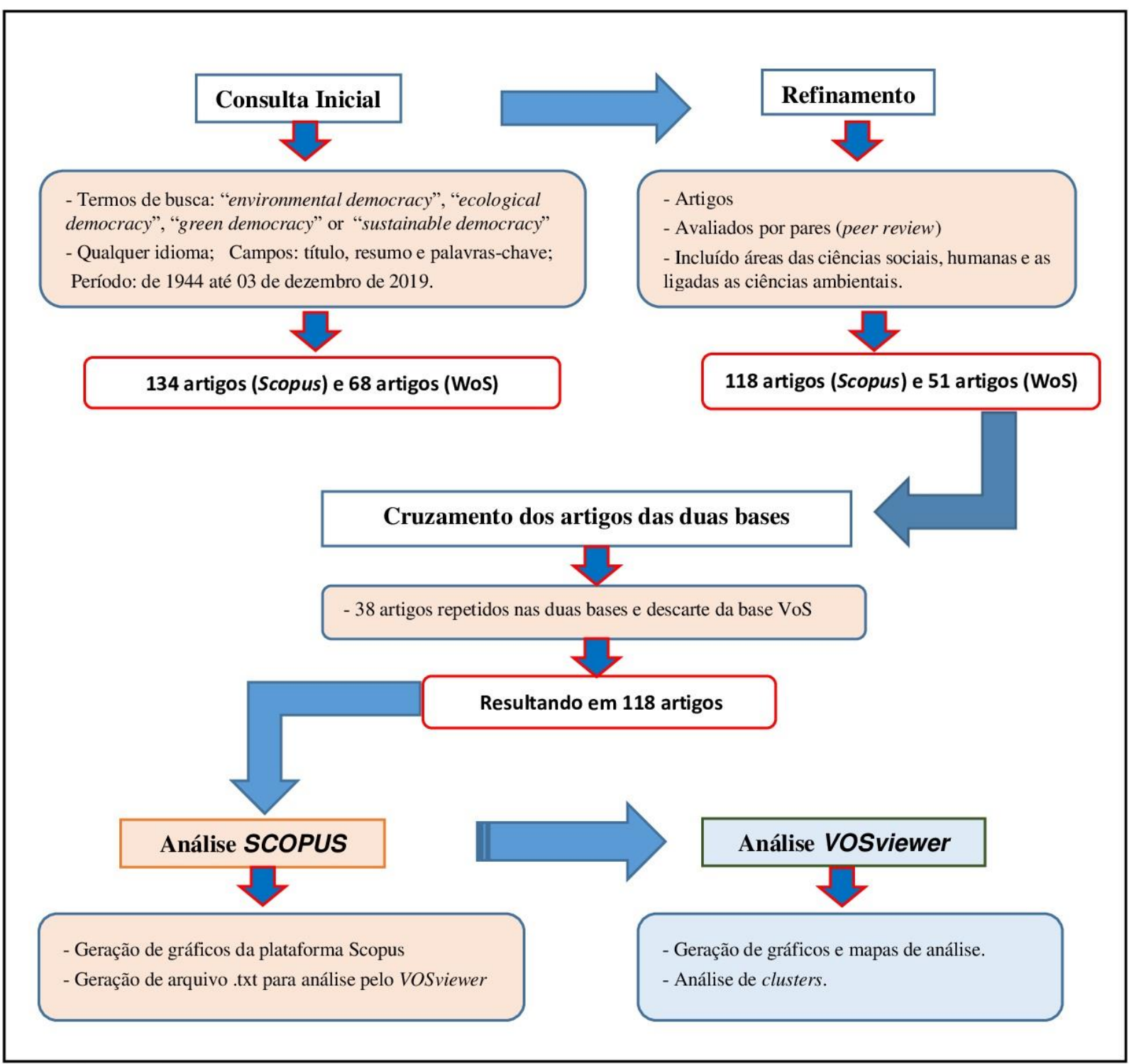

Fonte: Elaborado pelos autores (2019)

A análise dos dados obtidos (118 artigos) foi conduzida pelo procedimento bibliométrico, utilizando-se do software VOSviewer ${ }^{\circledR}$ versão 1.6.11, programa com foco na produção de similaridades na ocorrência de coautoria, citação, cocitação, acoplamento bibliográfico e coocorrência de palavras-chave por meio de mapeamentos de clusters, que apresentam maior e menor força e aproximação entre termos (van Eck \& Waltman, 2014). A escolha desse software decorre do seu livre acesso e da recorrência de uso em pesquisa bibliométrica na literatura (Medeiros Filho \& Russo, 2017; Abadia \& Carvalho, 2018; Espinosa et. al., 2020; Caro, et. al., 2020).

A análise textual dos artigos selecionados como destaques nessa pesquisa foi feita pela análise temática e interpretativa (Severino, 2018), buscando primeiro a apreensão do texto de 
acordo com a percepção do autor (tema ou assunto), ou seja, a ideia central do texto, depois, mediante a ideia do autor, fazer uma inferência e interpretação do que se apreciou, explicitando os pressupostos que o texto implica.

\section{Resultados e Discussão}

Identificar a tendência nas produções científicas requer a busca longitudinal, no caso das tendências das discussões acadêmicas sobre teorias ou conceitos ambientais ofereceram um duplo movimento contributivo, já que as produções científicas influenciaram e foram influenciadas pelos eventos, discussões e ações de atores no cenário nacional e internacional, que tem grande repercussão na década de 40 e segue até hoje com a instituição de conceitos ou teorias para explicar fenômenos ou solucionar problemas sociais, econômicos e ambientais. É o que se pode observar na transição de nomenclaturas e significações de sustentável, sustentabilidade e desenvolvimento sustentável (Feil \& Schreiber, 2017).

A análise bibliométrica foi dividida em dois momentos: o primeiro apresenta os dados encontrados quantitativamente com ênfase nos aspectos de crescimento quantitativo da produção, periódicos publicados, publicações por países, instituições de origem dos artigos e a frequência de termos. O segundo apresenta o aspecto qualitativo a partir do qual foi feita uma análise a partir das redes de autoria, coautoria e citações das produções científicas.

\subsection{Indicativos quantitativos da produção científica}

\section{$\underline{\text { 3.1.1 Crescimento quantitativo da produção }}$}

A compreensão do quantitativo de produções se mostra uma estratégia importante para compreender a ampliação ou não do debate sobre uma determinada temática no tempo, sendo possível fazer considerações como o nível de produtividade, aumento do fenômeno e o período de discussão do fenômeno na história. A distribuição das publicações sobre a relação democracia e meio ambiente pode ser visualizada na Figura 2, representada pelo gráfico de linha da quantidade de artigos publicados por ano. 
Research, Society and Development, v. 9, n. 7, e364974311, 2020

(CC BY 4.0) | ISSN 2525-3409 | DOI: http://dx.doi.org/10.33448/rsd-v9i7.4311

Figura 2 - Indicativos das publicações por ano.

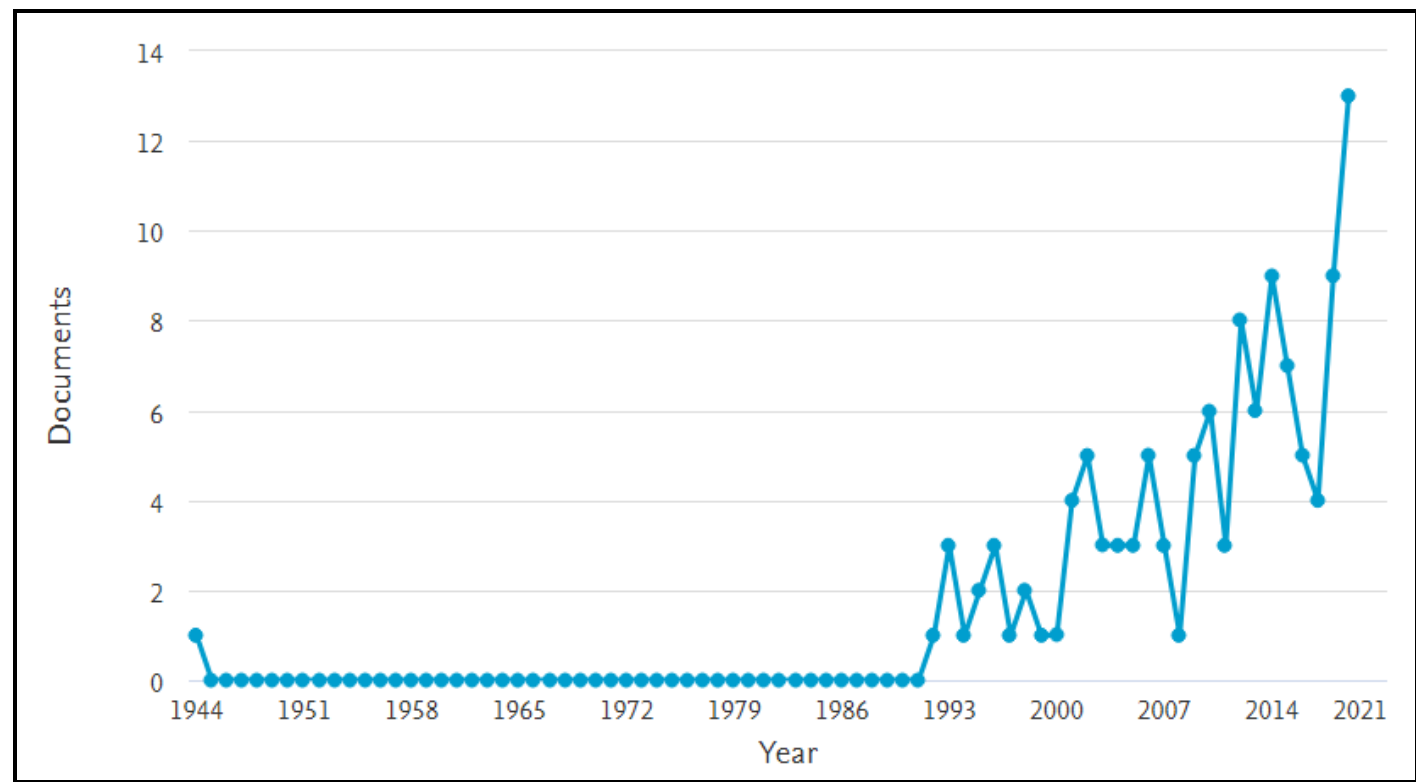

Fonte: Analyze search results (Scopus, 2019).

A primeira produção publicada, com os parâmetros de busca, foi em 1944 com o artigo intitulado Green Democracy (Culkin, 1944). Nessa produção Culkin discute a democracia sob a ótica de práticas realizadas por crianças e jovens. A democracia é vista como algo embrionário, em que os sujeitos (as crianças) se tornarão cidadãos (democráticos) pelas formas de democracia. O título democracia verde é empregado semanticamente pelo autor como algo que ainda não amadureceu ou que não tem experiência (imaturo, inexperiente, novo), estando dissociado das relações com as teorias ambientais ou verde.

Entre os anos de 1945 e 1991, não existe nenhum registro de publicação na plataforma da Scopus de artigos científicos com os termos de buscas. Porém, é importante lembrar que nesse espaço temporal ocorreram movimentos ambientais mundiais, como lembra Bursztyn e Bursztyn (2013) os debates internacionais sobre a proteção da natureza foram marcados na década de 40 com a Conferência das Nações Unidas sobre Conservação e Utilização de Recursos Naturais (1948). Posteriormente, ocorreram vários fatos, situações e debates que alertavam para as questões ambientais como Relatório do Clube de Roma (década de 60), Conferência de Estocolmo (década de 70), Relatório de Brundtland (década de 80) e a Conferência do Rio-92 (década de 90).

É em 1992, ano da Conferência do Rio-92, que ocorre novamente uma publicação com a utilização do termo democracia sustentável no artigo Authoritarian Rule and Democracy in Africa: A Theoretical Discourse (Bangura, 1992), havendo uma discussão sobre as raízes do autoritarismo e seu impacto nos caminhos da democratização estável e sustentável de países 
africanos, problemas enfrentados pela legitimação de regimes militares e de partido único, diante da crise do contrato social que assegurava os modelos de desenvolvimento póscoloniais.

A Figura 2 mostra o desempenho das publicações científicas sobre a relação democracia e meio ambiente revelando que entre os períodos de 1992 a 2014 houve uma oscilação no quantitativo de produções, e nesse período houveram picos em 1993 e 1996 (3 artigos cada), 2001 (4 artigos), 2002, 2006 e 2009 (5 artigos cada), 2010 (6 artigos), 2012 (8 artigos).

O crescimento de publicações ocorreu a partir de 2014, com uma maior publicação absoluta em 2019, com o quantitativo de 13 artigos científicos. Portanto, a tendência geral foi de um aumento da produção científica sobre a relação democracia e meio ambiente desde o ano de 2014.

\subsubsection{Periódicos publicados, publicações por países e instituições de origem}

A produção científica ocorre por meio de revistas ou periódicos científicos/acadêmicos no formato impresso como também no formato eletrônico, constituindo espaços de disseminação de informações e conhecimento. Identificar os periódicos, países e instituições científicas que publicam o tema democracia e meio ambiente pode revelar as tendências de áreas de publicação, os países que possuem interesse no tema e a existência de núcleos de estudos sobre o fenômeno nas instituições de pesquisa, a Tabela 1 apresenta os principais periódicos: 
Tabela 1. Publicação por periódicos.

\begin{tabular}{|c|c|c|}
\hline Periódico & Quantidade de Artigos & $\mathbf{J C R}^{1}$ \\
\hline Environmental Politics & 9 & 3.827 \\
\hline Environmental Values & 6 & 1.933 \\
\hline Journal Of Environmental Policy And Planning & 3 & 4.195 \\
\hline Democratization & 2 & 1.850 \\
\hline Development (Basingstoke) & 2 & S.I. \\
\hline Environmental Policy And Governance & 2 & 1.888 \\
\hline Futures & 2 & 2.214 \\
\hline Global Environmental Politics & 2 & 3.397 \\
\hline Organization And Environment & 2 & 8.500 \\
\hline $\begin{array}{l}\text { Review Of European Community And International } \\
\text { Environmental Law }\end{array}$ & 2 & S.I. \\
\hline Third World Quarterly & 2 & 2.156 \\
\hline Demais Periódicos (84 periódicos com um artigo cada) & 84 & $* * *$ \\
\hline $\begin{array}{ll}\text { Total } \\
\end{array}$ & 118 & $* * *$ \\
\hline
\end{tabular}

Fonte: Dados dos autores (2019)

O periódico Environmental Politics é o que apresenta maior quantidade de artigos, com nove artigos publicados e possui um Fator de Impacto $^{2}$ de 3.827, seguidos dos periódicos Environmental Values com seis artigos e Fator de Impacto de 1.933 e o Journal of Environmental Policy and Planning com três artigos e Fator de Impacto 4.195. Embora os três periódicos possuam mais artigos com o tema, eles não são os de maiores fatores de impactos. O periódico com maior fator de impacto é o Organization and Environment com fator 8.500 e possui dois artigos publicado sobre o tema. Isso significa que os periódicos que publicam mais artigos da temática não são aqueles reconhecidos como os periódicos que possuem maior prestígio acadêmico em termos quantitativos de citações recebidas.

É possível concluir que há uma dispersão de publicações, ou seja, não existe uma concentração em nenhum periódico, sendo identificados 95 periódicos distintos. Apesar de se tratar de um fenômeno de estudo interdisciplinar, esse tipo de publicação não é homogêneo em todas as áreas do conhecimento, tendo predominância em ciências sociais, econômicas e ciências ambientais. Essas áreas são as de maiores incidências de artigos, com foco nas discussão de políticas, valores e planejamentos ambientais.

Essas publicações científicas são contabilizadas pela plataforma Scopus a partir das afiliações dos autores, e por se tratar do maior banco de dados de resumos e citações de

\footnotetext{
${ }^{1}$ Journal Citation Reports (2018). www.webofknowledge.com > JCR

${ }^{2} \mathrm{O}$ fator de impacto é uma métrica para "avaliar, contabilizando as citações, revistas científicas dentro da cientometria, ramo da bibliometria que avalia publicações dentro da comunidade científica e auxilia na elaboração de políticas científicas" (Kishi, 2020, p.1)
} 
Research, Society and Development, v. 9, n. 7, e364974311, 2020

(CC BY 4.0) | ISSN 2525-3409 | DOI: http://dx.doi.org/10.33448/rsd-v9i7.4311

literatura com revisão por pares, é possível encontrar o cadastro de produções e periódicos de vários locais do mundo, assim como autores e redes de coautoria que estão afiliados em instituições dos cinco continentes, podendo ser visualizado na Figura 3.

Figura 3 - Publicação por país ou território de afiliação dos autores.

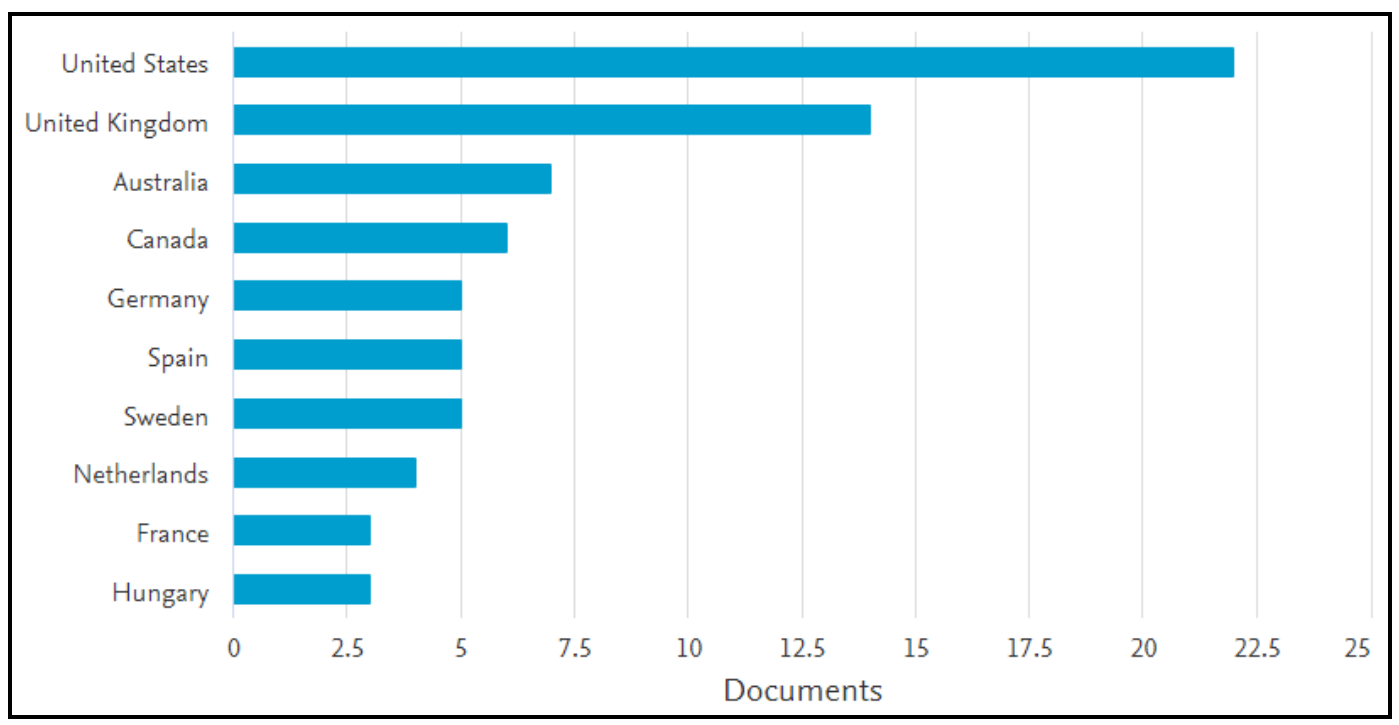

Fonte: Analyze search results (Scopus, 2019).

Foram encontrados na base Scopus uma quantidade de 122 instituições de afiliação dos autores e coautores presentes em 33 países definidos distribuídos em cinco continentes. Os 10 países com as maiores quantidades de publicações estão presentes nos continentes americano, europeu e na Oceania. Os três países com maiores números de produções foram os Estados Unidos (22 artigos), Reino Unido (14 artigos) e Austrália (7 artigos).

A representação desses países com maior número de publicações podem ser explicados por fatores como: a busca por termos e artigos oriundos da língua inglesa, (linguagem oficial desses três países); a grande quantidade de revistas estrangeiras (de língua inglesa) estarem vinculadas à plataforma Scopus, também é um fator a ser levado em consideração, de modo que os periódicos que não estejam vinculados a base de dados estariam fora da base de busca. Por outro lado, esses três países (assim como países desenvolvidos) possuem políticas universitárias, cultura e apoio à produção científica maior que os países emergentes (ou em desenvolvimento). Isso pode ser observado no Quadro 1 quando se observa as instituições que mais produzem artigos sobre esse tema. 
Quadro 1. Documentos por afiliação institucional.

\begin{tabular}{|l|c|c|}
\hline Instituições & Quantidade de Artigos & País \\
\hline University of Melbourne & $\mathbf{3}$ & Austrália \\
\hline Budapest Corvinus Egyetem & 2 & Hungria \\
\hline Universidad de Malaga & 2 & Espanha \\
\hline Wageningen University and Research Centre & 2 & Holanda \\
\hline Franklin and Marshall College, Lancaster & 2 & Estados Unidos \\
\hline The University of British Columbia & 2 & Canadá \\
\hline The University of Warwick & 2 & Reino Unido \\
\hline University of Canberra & 2 & Australia \\
\hline Instituições (continuação) & 2 & País \\
\hline University of Connecticut & 2 & Estados Unidos \\
\hline Universidad Autónoma de Madrid & $1^{*}$ & Espanha \\
\hline Demais instituições (total de 112) & & Variados \\
\hline
\end{tabular}

Fonte: Dados da pesquisa

Quanto à produção por instituição de origem dos autores, a universidade australiana de Melbourne tem uma maior quantidade de artigos publicados, três artigos: Political and Ecological Communication (Dryzek, 1995), From the liberal to the green democratic state: Upholding autonomy and sustainability (Eckersley, 2006) e Ecological democracy and the rise and decline of liberal democracy: looking back, looking forward (Eckersley, 2019). Importante mencionar que os dois autores Dryzek e Eckersley são representativos nas temáticas envolvendo a relação democracia e meio ambiente, ao discutir assuntos como a democracia ecológica, estado democrático verde e política ecológica/verde.

É possível considerar que não há concentração de estudos sobre democracia e meio ambiente em nenhuma universidade ou país. Ainda que os Estados Unidos tenham se apresentado como o país mais produtivo no tema, sua produção não é homogênea, estando dispersa em diversas universidades ou instituições de pesquisa no país, não havendo concentração de relevância quantitativa em nenhuma instituição de pesquisa norte-americana. O mesmo entendimento vale para o Reino Unido e para a Austrália.

Porém, essa pluralidade de instituições e de países de diversos continentes produzindo sobre democracia e meio ambiente, podem traduzir uma visão cultural diversificada sobre a temática, posto que os regimes, forma e sistemas de governo e de Estados são distintos e podem trazer uma visão conceitual multifacetada sobre os termos democracia verde, ecológica sustentável e ambiental, assim como experiências distintas sobre os modelos de democráticos e sua relação com o meio ambiente. É possível fazer uma comparação e distinção das formas democráticas quando se trata não apenas da cultura do povo (ambiente cultural), mas da aplicação (metodologia) ou experiência de países com diferentes ecossistemas e biodiversidades. 


\section{$\underline{\text { 3.1.3 Temas de pesquisas }}$}

Os temas centrais das pesquisas são uma das possibilidade de visualizar quais termos são mais usuais nos artigos, sendo interessante considerar essas ocorrências de termos nos campos dos títulos e resumos.

Para tanto, criou-se no software VOS Viewer um mapa, adotando como critérios: o campo do título e resumo (title e abstract fields), ignorando os resumos estruturados e declaração de direitos autorais (Ignore structured abstract labels e copyright statements) e adotando o método de contagem completa.

Tomou-se como limite para geração do mapa: o número mínimo de 10 ocorrências de termos e o agrupamento por similaridade que resultou em 56 termos, porém, foram selecionados 34 termos mais relevantes (60\%) para a geração do mapa e discussão temática com os descritores selecionados, conforme a Figura 4.

Figura 4. Clusters de termos de maior coocorrência nos títulos e resumos.

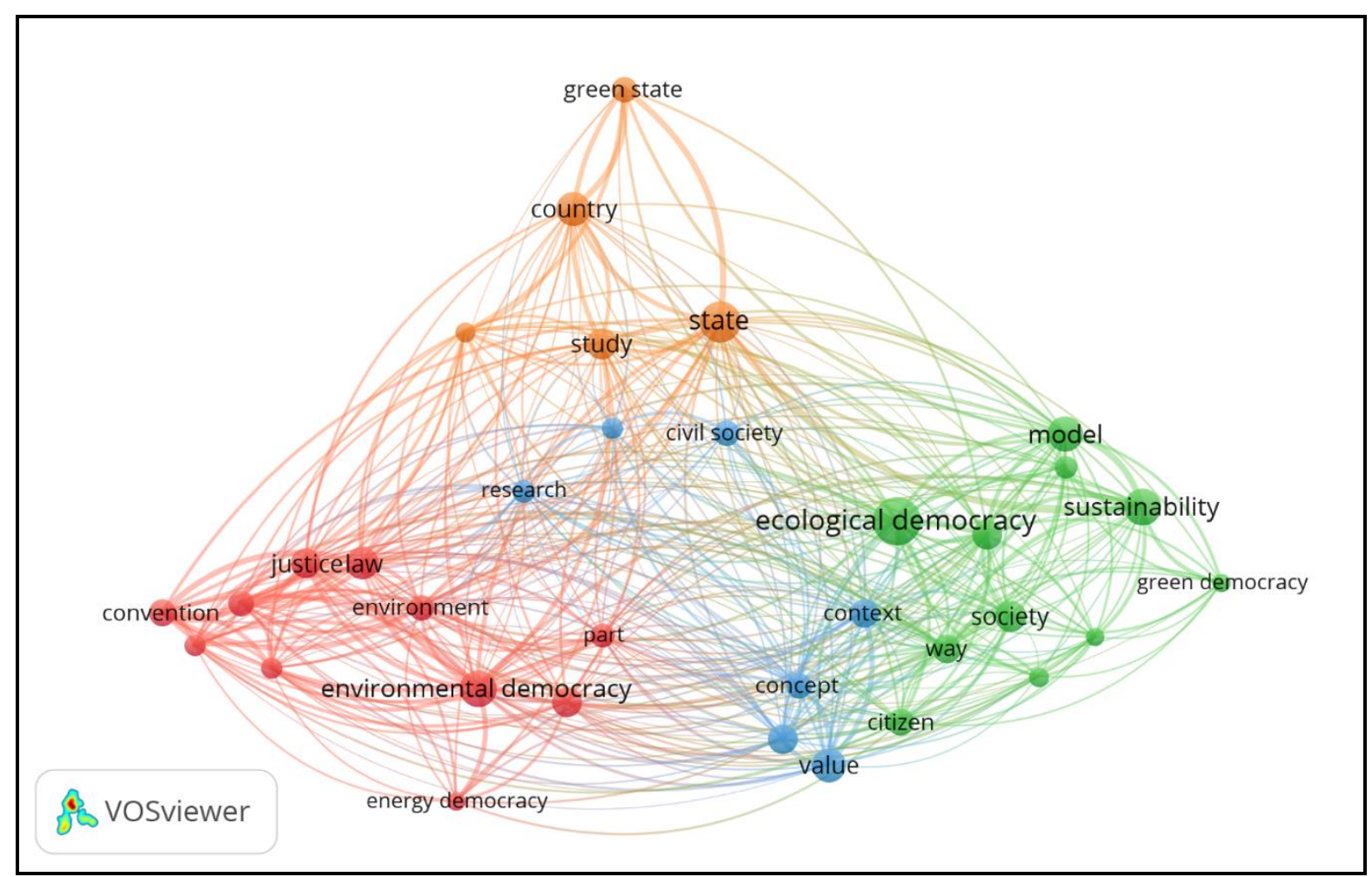

Fonte: VOS Viewer, versão 1.6.11; Scopus, usando as strings de consulta "environmental democracy" ou "ecological democracy" ou "green democracy" ou "sustainable democracy" desde 1944 até 2019.

A análise do VOS Viewer fornece-nos clusters (grupos) dos termos de maior ocorrência nos títulos e resumos dos artigos científicos (papers), apresentando-se pela frequência em que são citadas conjuntamente e a proximidade entre os termos, mostra um 
(CC BY 4.0) | ISSN 2525-3409 | DOI: http://dx.doi.org/10.33448/rsd-v9i7.4311

nível de similaridade semântica em um grupo e/ou correlação de ideias de um grupo (Caro, et. al., 2020).

O grafo (Figura 4), de dados da Scopus, com os termos de coocorrência nos títulos e resumos, possui um total de 34 itens e 4 clusters $(1$ - vermelho, 2 - verde, 3 - azul e 4 laranja) tendo no maior deles 11 termos e, no menor, 5. É possível visualizar os termos mais representativos sendo: ecological democracy (cluster 2), state (cluster 4), sustainability (Cluster 2), environmental democracy (Cluster 1) e model (Cluster 2). É possível perceber que o cluster 2 (verde) é o que possui 3 itens dos 5 mais representativos do grafo, o que revela um maior quantitativo de produções e frequência de termos em pesquisas associadas à temática da democracia ecológica.

Os agrupamentos formados pelas coocorrências de termos no mapa, a priori, nos permite inferir a aproximação (ou estabelecimento de relação) entre os clusters, destacando os dois termos-chave de busca dessa pesquisa enviromental democracy (Cluster 1) e ecological democracy (Cluster 2), estabelecendo uma relação de maior vínculo entre os termos dos seus clusters, identificando elementos que constroem esses termos intrínseco como propriedade e/ou características. Muito embora os dois clusters estabeleçam ligações e pertencimentos de termos (micro termos) um ao outro.

O mapa de termos de coocorrência (Figura 4) e os clusters gerados podem ser detalhados e nomeclaturados com os termos âncoras de cada agrupamento no Quadro 2.

Quadro 2. Detalhamento dos clusters da Figura 4.

\begin{tabular}{|l|l|l|l|}
\hline \multicolumn{1}{|c|}{ Cluster 1 } & \multicolumn{1}{|c|}{ Cluster 2 } & \multicolumn{1}{c|}{ Cluster 3 } & \multicolumn{1}{c|}{ Cluster 4 } \\
\hline Democracia Ambiental & Democracia Ecológica & \multicolumn{1}{c|}{ Conceito e Valores } & \multicolumn{1}{c|}{ Estado } \\
\hline Access & citizen & civil society & Country \\
convention & deliberative democracy & concept & gonironmental \\
energy democracy & democratisation & context & green state \\
environment & ecological democracy & latin america & state \\
enviromental democracy & green democracy & participation & study \\
information & model & research & \\
justice & value & \\
law & & \\
part & relation & & \\
policy & society & & \\
public participation & sustainability & way & \\
\hline
\end{tabular}

Fonte: Dados da pesquisa

O cluster 1 (vermelho), nominado de Democracia Ambiental, é formado pelo macro termo enviromental democracy, por sua força de ligação (strength 390) e pela quantidade de ligações (30) com outros termos de seu grupo e dos outros três clusters. O cluster é formado 
pelas relações estabelecidas entre o macro termo democracia ambiental e pelos termos: acesso (access), informação (information), meio ambiente (environmental), convenção (convention), justiça (justice) e lei (law), que estabelecem ligações e referências às dimensões da “democracia ambiental" estabelecida na convecção do Rio-92, Acordo de Escazú e Convenção de Aarhus.

O cluster 2 (verde), nominado de Democracia Ecológica, é estabelecido pelo macro termo ecological democracy que possui força de ligação (strength) 278 e maior ocorrência (65) do clusters. O cluster é composto por outro termo objeto dessa investigação: green democracy (democracia verde), possuindo uma ocorrência (10), força de ligação (strength 91) e quantidade de ligação (14) menor do que o macro termo do cluster, e se comunicando mais com os termos de dentro do cluster verde, do que com os dos outros três clusters.

Os termos concept e value no cluster 3 (azul), são os termos mais representativos do grupo, por isso sua nomeação com esses termos. O termo concept com 18 ocorrências, força (strength) 213 e 28 ligações - fazendo ligação com todos os termos do cluster azul - e, value, com 32 ocorrências, força (strength) 277 e 23 ligações. O cluster Conceitos e valores pode ser considerado como um grupo de transição por estabelecerem maior vínculo de ligações com termos dos clusters 1 (vermelho), 2 (verde) e 4 (laranja).

Já o cluster 4 (laranja), nomeado de Estado, tem o termo State (strength 377) como um central por se ligar a todos os termos do cluster, com 32 ligações e 48 ocorrências, e ainda estabelecendo ligação direta com os termos centrais do cluster 1 (vermelho) - enviromental democracy, cluster 2 (verde) -ecological democracy e cluster 3 (azul) - concept e value, podendo-se inferir que os termos desse cluster se configuram como estruturação e formalização dos elementos governamentais e democráticos de governo e de Estado. Dessa forma, é possível entender esse cluster como a finalidade da relação democracia e meio ambiente, que possivelmente seriam elementos e propósitos para a criação de um Estado verde, sustentável, ecológico ou ambiental.

\section{$\underline{3.2 \text { Indicativos qualitativos da produção científica: Redes de autoria, coautoria e citações }}$}

O fator de impacto é medido pelo número médio de citações recebidas em um período de tempo pelo artigo. Desta forma, visualizar o número de citações de artigos publicados se mostra relevante para identificação dos trabalhos e autores com maior destaque no âmbito de um determinado tema de pesquisa, estabelecendo, por vezes, um status de referência para a discussão. 
Research, Society and Development, v. 9, n. 7, e364974311, 2020

(CC BY 4.0) | ISSN 2525-3409 | DOI: http://dx.doi.org/10.33448/rsd-v9i7.4311

Com vistas a investigar quais os autores de destaque no tema da relação democracia e meio ambiente, criou-se no software VOS Viewer um mapa com base em dados bibliográficos. Foram adotados os seguintes critérios: 1) o tipo de análise de coautoria (Coauthorship); 2) o autor na unidade de análise; 3) o método de contagem completa; 4) ignorar documentos com um grande número de autores, por isso o número máximo de autores por documento foi de cinco; 5) o número mínimo de um documento por autor; e 6) o número mínimo de 29 (vinte e nove) citações de um autor, por ser o limite dos dez artigos mais citados (Quadro 3). Com os critérios adotados foi possível encontrar 18 autores mais relevantes para a discussão temática democracia e meio ambiente, conforme a Figura 5.

Figura 5.Clusters de citações de maior co-ocorrência por autor.

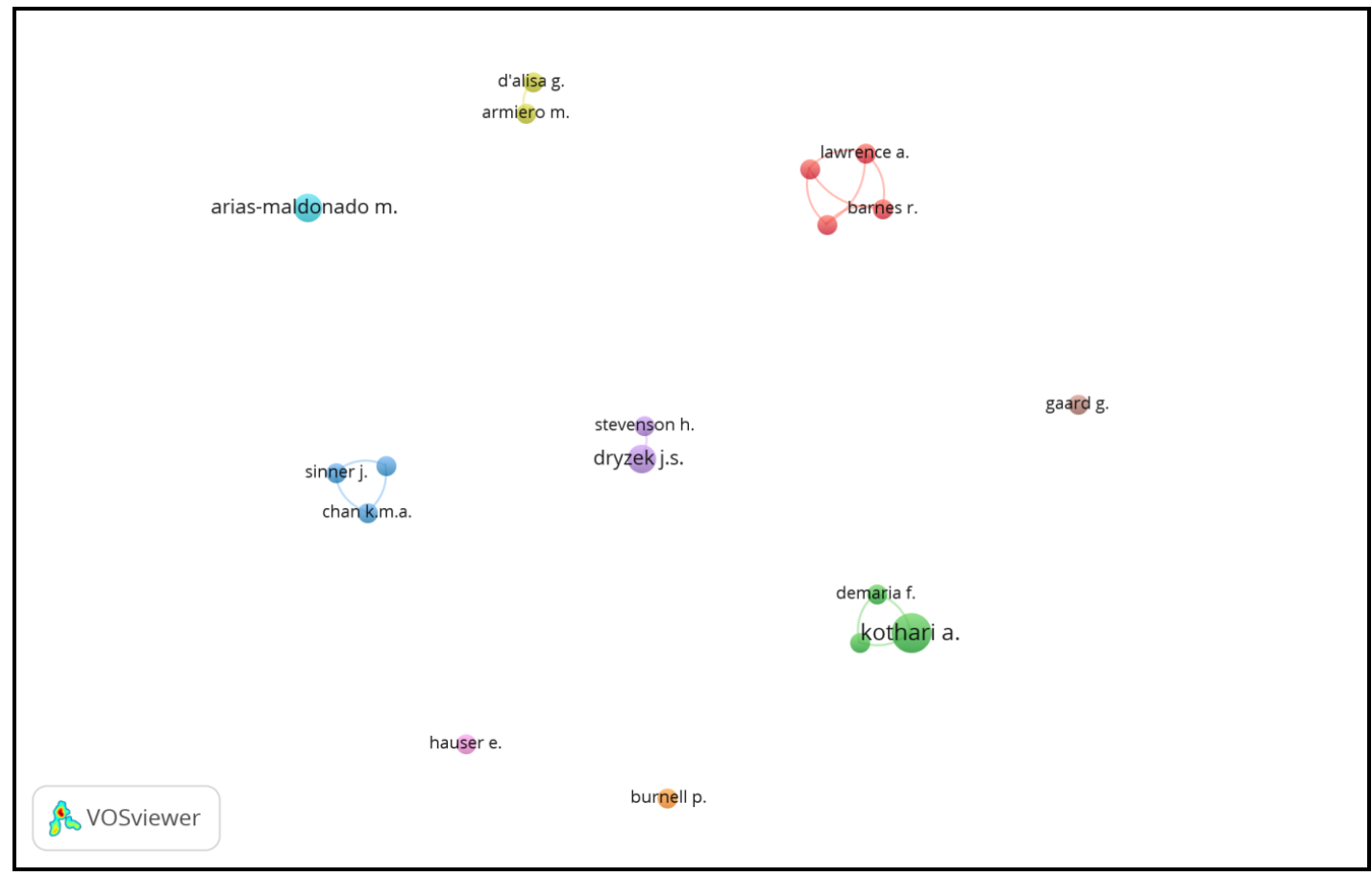

Fonte: VOS Viewer, versão 1.6.11; Scopus, usando as strings de consulta "environmental democracy" ou "ecological democracy" ou "green democracy" ou "sustainable democracy" desde 1944 até 2019.

Os 18 autores foram agrupados conforme suas parcerias de produção científica, formando 9 clusters com documentos de autores que mais se destacaram com o índice mínimo de 29 citações. O detalhadamente desse grafo (Figura 5) é feito no Quadro 3, ao se estabelecer em ordem decrescente os dez artigos com maiores quantidades de citações, e seus respectivos autores e periódicos publicados. 
Research, Society and Development, v. 9, n. 7, e364974311, 2020

(CC BY 4.0) | ISSN 2525-3409 | DOI: http://dx.doi.org/10.33448/rsd-v9i7.4311

Quadro 3. Autores, artigos, periódicos e número de citações.

\begin{tabular}{|l|l|l|c|}
\hline \multicolumn{1}{|c|}{ Autor } & \multicolumn{1}{|c|}{ Título do Artigo } & \multicolumn{1}{c|}{ Periódico } & Citações \\
\hline $\begin{array}{l}\text { Dryzek \& } \\
\text { Stevenson (2011) }\end{array}$ & Global democracy and earth system governance & $\begin{array}{l}\text { Ecological } \\
\text { Economics }\end{array}$ & 130 \\
\hline Dryzek (1995) & Political and Ecological Communication & $\begin{array}{l}\text { Environmental } \\
\text { Politics }\end{array}$ & 54 \\
\hline $\begin{array}{l}\text { Kothari, Demaria } \\
\text { \& Acosta (2014) }\end{array}$ & $\begin{array}{l}\text { Buen Vivir, Degrowth and Ecological Swaraj: } \\
\text { Alternatives to sustainable development and the Green } \\
\text { Economy }\end{array}$ & $\begin{array}{l}\text { Development } \\
\text { (Basingstoke) }\end{array}$ & 53 \\
\hline Burnell (2001) & $\begin{array}{l}\text { The party system and party politics in Zambia: } \\
\text { Continuities past, present and future }\end{array}$ & African Affairs & 50 \\
\hline Hauser (1999) & $\begin{array}{l}\text { Ugandan relations with western donors in the 1990s: } \\
\text { What impact on democratisation? }\end{array}$ & $\begin{array}{l}\text { Journal } \\
\text { Modern African } \\
\text { Studies }\end{array}$ & 46 \\
\hline $\begin{array}{l}\text { Armiero } \\
\text { D'Alisa (2012) }\end{array}$ & $\begin{array}{l}\text { Rights of resistance: The garbage struggles for } \\
\text { environmental justice in Campania, Italy }\end{array}$ & $\begin{array}{l}\text { Capitalism, } \\
\text { Nature, Socialism }\end{array}$ & Citações \\
\hline $\begin{array}{l}\text { Arias-Maldonado } \\
\text { (2007) }\end{array}$ & $\begin{array}{l}\text { An imaginary solution? The green defence of } \\
\text { deliberative democracy }\end{array}$ & $\begin{array}{l}\text { Environmental } \\
\text { Values }\end{array}$ & 36 \\
\hline Gaard (2001) & $\begin{array}{l}\text { Women, water, energy: An ecofeminist approach } \\
\text { Organization and } \\
\text { Environment }\end{array}$ & 34 \\
\hline $\begin{array}{l}\text { Tadaki, Sinner \& } \\
\text { Chan (2017) }\end{array}$ & $\begin{array}{l}\text { Making sense of environmental values: A typology of } \\
\text { concepts }\end{array}$ & $\begin{array}{l}\text { Ecology and } \\
\text { Society }\end{array}$ & 29 \\
\hline $\begin{array}{l}\text { Lawrence, } \\
\text { Paudel, Barnes \& } \\
\text { Malla (2006) }\end{array}$ & $\begin{array}{l}\text { Adaptive value of participatory biodiversity monitoring } \\
\text { in community forestry }\end{array}$ & $\begin{array}{l}\text { Environmental } \\
\text { Conservation }\end{array}$ & 29 \\
\hline
\end{tabular}

Fonte: Elaborado pelos autores com os dados da pesquisa (2020)

Dentre os artigos mais citados, apenas dois estão contidos entre os três periódicos que apresentam maior quantidade de publicações sobre a temática (Tabela 1), que são Environmental Politics e Environmental Values. Sobre o tema existe uma pulverização das produções nos periódicos, podendo-se observar que os clusters com autores mais citados, não estão com suas publicações entre os periódicos mais relevantes em termos de quantitativo de publicação.

Além de entender sobre a produção em termos quantitativo, é preciso discutir a abordagem de conhecimento produzido em cada cluster, como se configuram essas redes de colaboração entre autores e como se comunicam ou corroboram os pesquisadores desses clusters. Perceber essa configuração é um indicativo de como tem sido articulada a divulgação, alcance e a construção do conhecimento científico sobre a relação democracia e meio ambiente.

O Cluster 1 é representado pela colaboração dos pesquisadores Lawrence, Paudel, Barnes \& Malla (2006), com uma pesquisa-ação qualitativa realizada no distrito de Baglung 
(Nepal) com Grupos de Usuários Florestais (FUGs), silvicultores e partes interessadas. A pesquisa utiliza apenas o termo "democracia ambiental" nas palavras-chaves, e os autores não fazem um aprofundamento na discussão no decorrer do texto sobre as perspectivas teóricopráticas da democracia ambiental, o foco do estudo se pauta no vínculo entre participação e conservação, pelos efeitos da estrutura do monitoramento, aprendizado e comunicação de valores de biodiversidade de atores sociais para estimular a conservação das florestas. Os autores defendem a não dissociabilidade dos conhecimentos sociais e técnicos, pois entendem que o manejo florestal mais democrático e o monitoramento participativo ajudam os atores sociais a contribuir no processo de conservação ambiental.

O pesquisador Kothari e seus colaboradores formam o Cluster 2 com quatro publicações. Kothari (2009, 2014ab) aparece como autor em três artigos publicados nos periódicos Development (2009), Development (Basingstoke) (2014) e Futures (2014), intitulados: Radical ecological democracy: Escaping India's globalization trap (2009), India 2100: Towards Radical Ecological Democracy (2014a) e Radical Ecological Democracy: A path forward for India and beyond (2014b).

Nessas publicações, Ibid (2009, 2014ab), apresenta os problemas enfrentados pelo processo de globalização na Índia, pontuando como as crises econômicas e ambientais afetam o estilo de vida das pessoas e o 'desenvolvimento' indiano.

$\mathrm{O}$ autor enxerga as diversas crises existentes como uma oportunidade de reorientação da economia, das relações sócio-políticas e das visões e atitudes com relação ao meio ambiente. Por isso aponta dois princípios fundamentais na mudança de rumos dos indianos, que são: a sustentabilidade ecológica e a equidade social. Para superar o estágio atual de desigualdade social e desgaste ambiental o autor propõe um conceito teórico de Democracia Ecológica Radical (RED), que diferente do modelo democrático representativo eleitoral, esse busca reverte alguns efeitos da globalização, focando no aumento do poder decisório local, com economias localizadas e estilos de vida éticos, mudando o olhar das relações.

Kothari (2014ab) também faz uma reflexão sobre as possíveis mudanças sociais, econômicas e ambientais ocorridas na Índia (e no mundo) e os efeitos decorrentes dos atuais modelos de exploração, apresentando uma previsão de três possíveis cenários que a sociedade poderá seguir no futuro. Uma possível mudança seria a implementação de uma Democracia Ecológica Radical (RED), caracterizada pela descentralização (de estruturas de governança de níveis locais até espaços maiores) e incorporação do coletivo e das comunidades no centro da governança e da economia, estando estruturada no bem-estar humano com a participação da tomada de decisões com base nos pilares da sustentabilidade ecológica e da equidade humana. 
A sustentação desse pensamento teórico assenta-se em um conjunto de princípios, já existentes, oposto (ou que estão faltando) nos modelos atuais de relações socioeconômico e ambiental.

Enquanto a parceria internacional de Kothari com os pesquisadores Demaria e Acosta (2014), da UAB Institut de Ciència i Tecnologia Ambientals (Cerdanyola del Valles, Spain) e Latin American Faculty of Social Sciences (Quito, Ecuador), respectivamente, intitulado de Buen Vivir, Degrowth and Ecological Swaraj: Alternatives to sustainable development and the Green Economy (2014), tecem críticas aos conceitos e modelos da Economia Verde e Desenvolvimento Sustentável, visando desconstruir e desafiar a ideia dominante de desenvolvimento pregada pelo Ocidente, apontam três visões de mundo ou alternativas de bem-estar emergente (ou reemergente) existente em várias regiões, focando no Buen Vivir (América Latina), Degrowth ou decrescimento (Europa) e Ecological Swaraj ou Democracia Ecológica Radical(Índia), como uma possível resposta a (in)sustentabilidade e desigualdade ocasionada pelos modelos de 'desenvolvimento' atual.

No Cluster 3, os pesquisadores Tadaki, Sinner e Chan (2017) apresentam um estudo que elucida o termo Democracia Ambiental pelo reconhecimento das aplicações de valores (ou valorização) ambientais, mediante uma tipologia de aspectos conceituais e metodológicos de quatro conceitos de valores (magnitude de preferência, contribuição para uma meta, prioridades individuais ou relações) como uma "tecnologia de participação" para o exercício das tomadas de decisões nas gestões ambientais.

O cluster 4 apresenta o termo Democracia Ecológica em uma parceria entre Armiero e D'Alisa (2012) com o foco do estudo sobre conflitos de justiça ambiental, estado de emergência e a questão das disposições de resíduos sólidos na região de Campania (Itália). Para os autores, a questão do estado de emergência gera uma despolitização da questão dos resíduos, que tem causado danos para as classes mais pobres da região, frente ao não envolvimento direto dos cidadãos no planejamento e gestão de resíduos, criando-se, assim, uma crise de democracia. Nessa perspectiva, os conflitos são vistos pelos autores como oportunidade para novas formas de participação, entendendo que a ênfase da democracia ecológica está no ativismo, nos movimentos sociais e nas lutas sociais por justiça ambiental.

Dryzek (1995) e sua colaboração com Stevenson (2011) representam o cluster 5, a produção individual de Dryzek (1995) faz a relação democracia e meio ambiente apresentando os termos democracia verde e democracia ecológica como um caminho a ser tomado pela política governamental e organizações econômicas estabelecida pelo surgimento de movimentos sociais e partidos políticos verdes. O pesquisador Dryzek é um dos pioneiros 
nas discussões sobre as tensões entre os processos democráticos e a busca pelos resultados verdes. Nesse ensaio teórico ele encontra base na teoria política ambiental, racionalidade ecológica e da racionalidade comunicativa habermasiana como caminho para estabelecer esse elo pela integração da comunicação política e ecológica transcendendo as fronteiras do mundo humano.

A parceria Dryzek e Steverson (2011) discute a democracia ecológica na perspectiva da governança global das mudanças climáticas. Os autores entendem que os sistemas deliberativos terrestres, em resposta às questões climáticas, encontra a formação de dimensões analíticas de natureza econômica ou política e de ordem conservadora ou progressista, cujo cruzamento dessas dimensões forma uma tipologia de quatros discursos climáticos (sustentabilidade, sustentabilidade expansiva, discurso de limites e radicalismo verde).

Ao analisar com base nessa tipologia os discursos de atores nas conferências da $O N U$ sobre mudanças climáticas, que embora houvesse presença da sociedade civil no evento, a sua participação nas negociações ainda era limitada, alguns discursos (ex. radicalismo verde) não conseguiam passar de maneira eficaz, e existem problemas nas transmissões das discussões do espaço público para o espaço habilitado. Com isso os autores preveem possibilidades, limitações e práticas democráticas para uma política ambiental global.

Arias-Maldonado (2000, 2007), representando o Cluster 6, em seus dois artigos propõe o estabelecimento de modelo democrático verde, fundamentando-se na concepção deliberativa de democracia e na teoria política verde, esse modelo é baseado na combinação de dois princípios: sustentabilidade (normativa) e democratização da democracia. O autor sugere que a democracia verde deve surgir dentro de um modelo deliberativo de democracia, por estar estruturada na teoria da razão prática, pelo caráter inclusivo (de escutar vozes tradicionalmente excluídas) e ampliação da comunidade por meio da racionalidade comunicativa (Dryzek, 1995), características adequadas para se realizar a racionalidade ecológica.

Burnell (2001), cluster 7, apresenta o termo democracia sustentável ligado à organização política da Zâmbia (África) após eleições de 2001. Com a volta da legalidade do pluralismo político após um período de Estado monopartidário, o autor procura entender se existe uma contribuição do sistema partidário para transição e consolidação da democracia no país, e na lição da Zâmbia, as variedades predominantes de sistemas partidários não garantem um governo responsável e tão pouco o processo eleitoral não se tornou condições suficientes para institucionalizar a democracia liberal. Entretanto, encontra na sociedade civil o ente que garante melhor segurança para uma democracia saudável. 
O cluster 8 é composto pelo trabalho de Gaard (2001), autora que teoriza sobre o ecofeminismo, ao relacionar a exploração da natureza com a opressão de gêneros e outras formas como racismo, classe social, orientação sexual, colonialismo (índios) e neocolonialismo nas sociedades patriarcais, baseando-se em uma relação de poder estruturada entre dominante e dominado. A autora em seu artigo utiliza a teoria ecofeminista para defender uma democracia ecológica, ilustrando o problema da poluição da água e da produção energética, a partir do "modelo mestre de Plumwood" explica que a estrutura das culturas ocidentais são marcadas por dualismos em situações de (in)justiça ambiental, como: a associação histórica entre as mulheres e a água (mãe natureza) e a desvalorização de ambas (sendo vista como um servo da população dominante) representa o sexismo ambiental; a associação entre as pessoas de cor e a natureza como subordinadas aos interesses dominantes, com a eliminação de resíduos tóxicos e localização de indústrias poluidoras em comunidades de cor, representa o racismo ambiental; e, quando empresas localizam seus empreendimentos (usinas de energias) em comunidades rurais, consumindo os recursos (água, poluindo terras) afetando a saúde da população ao passo que transfere os ganhos (energia) para os centros urbanos (mais ricos) caracteriza o classismo ambiental. O pensamento da cultura ocidental é baseada na dominação (exploração da natureza, água, pessoas pobres, mulheres, etc.) para garantir recursos (energia e água potável).

Por fim, Hauser (1999), no cluster 9, aborda a introdução da democracia multipartidária a partir do relacionamento política externa (doador-receptor) que impunha condicionalidade política para os países da África Subsaariana em colocar reformas democráticas. Embora Uganda não tenha recebido essas condicionantes políticas, o autor entende que essa estratégia de países doadores ocidentais tornou-se um problema para a manutenção de uma democracia sustentável a longo prazo em países africanos. 
Research, Society and Development, v. 9, n. 7, e364974311, 2020

(CC BY 4.0) | ISSN 2525-3409 | DOI: http://dx.doi.org/10.33448/rsd-v9i7.4311

Quadro 4. Síntese das discussões dos clustes de citações.

\begin{tabular}{|c|c|c|}
\hline Cluster & Autor(es) & Debates centrais \\
\hline 01 & $\begin{array}{l}\text { Lawrence, Paudel, Barnes e } \\
\text { Malla (2006) }\end{array}$ & $\begin{array}{l}\text { Democracia Ambiental } \\
\text { - Valores ambientais e conservação } \\
\text { - Monitoramento Participativo de atores locais } \\
\text { - Indissociabilidade dos conhecimentos sociais e técnicos }\end{array}$ \\
\hline 02 & $\begin{array}{l}\text { Kothari }(2009,2014 \mathrm{ab}) \\
\text { Kothari, Demaria e Acosta } \\
(2014)\end{array}$ & $\begin{array}{l}\text { Democracia Ecológica } \\
\text { - Democracia Ecológica Radical (RED) } \\
\text { - Aumento do poder decisório local - incorporação do coletivo e } \\
\text { das comunidades no centro da governança e da economia } \\
\text { - Economias localizadas } \\
\text { - Buen Vivir (América Latina) } \\
\text { - Degrowth/decrescimento (Europa) }\end{array}$ \\
\hline 03 & Tadaki, Sinner e Chan (2017) & $\begin{array}{l}\text { Democracia Ambiental } \\
\text { - Valores (ou valorização) ambientais } \\
\text { - "Tecnologia de participação" }\end{array}$ \\
\hline 04 & Armiero e D'Alisa (2012) & $\begin{array}{l}\text { Democracia Ecológica } \\
\text { - Justiça ambiental } \\
\text { - Disposições de resíduos sólidos } \\
\text { - Danos para as classes mais pobres } \\
\text { - Ativismo, movimento sociais e lutas sociais }\end{array}$ \\
\hline 05 & $\begin{array}{lrll}\text { Dryzek }(1995), & \text { Dryzek } & \text { e } \\
\text { Steverson }(2011) & & \end{array}$ & $\begin{array}{l}\text { Democracia Verde e Democracia Ecológica } \\
\text { - Movimentos sociais e partidos políticos verdes } \\
\text { - Teoria política ambiental, racionalidade ecológica e da } \\
\text { racionalidade comunicativa habermasiana } \\
\text { Governança global das mudanças climáticas } \\
\text { - Discursos climáticos (sustentabilidade, sustentabilidade } \\
\text { expansiva, discurso de limites e radicalismo verde) } \\
\text { - Espaço público e espaço habilitado } \\
\text { - Limitações e práticas democráticas }\end{array}$ \\
\hline Cluster & Autor(es) & Debates centrais \\
\hline 06 & $\begin{array}{l}\text { Arias-Maldonado } \\
\text { 2007) }\end{array}$ & $\begin{array}{l}\text { Democracia Verde } \\
\text { - Teoria política verde } \\
\text { - Sustentabilidade (normativa) } \\
\text { - Democratização da democracia } \\
\text { - Democracia deliberativa } \\
\text { - Racionalidade comunicativa }\end{array}$ \\
\hline 07 & Burnell (2001) & $\begin{array}{l}\text { Democracia Sustentável } \\
\text { - Legalidade do pluralismo político } \\
\text { - África } \\
\text { - Estado monopartidário } \\
\text { - Sistema partidário } \\
\text { - Processo eleitoral } \\
\text { - Democracia liberal } \\
\text { - Sociedade civil } \\
\text { - Democracia saudável }\end{array}$ \\
\hline 08 & Gaard (2001) & $\begin{array}{l}\text { Democracia Ecológica } \\
\text { - Ecofeminismo } \\
\text { - Sociedades patriarcais } \\
\text { - Dominante e dominado } \\
\text { - "Dualismos" } \\
\text { - (in)justiça ambiental } \\
\text { - Sexismo ambiental } \\
\text { - Racismo ambiental } \\
\text { - Classismo ambiental }\end{array}$ \\
\hline 09 & Hauser (1999) & $\begin{array}{l}\text { Democracia Sustentável } \\
\text { - Democracia multipartidária } \\
\text { - Política externa (doador-receptor) } \\
\text { - Condicionalidade política }\end{array}$ \\
\hline
\end{tabular}




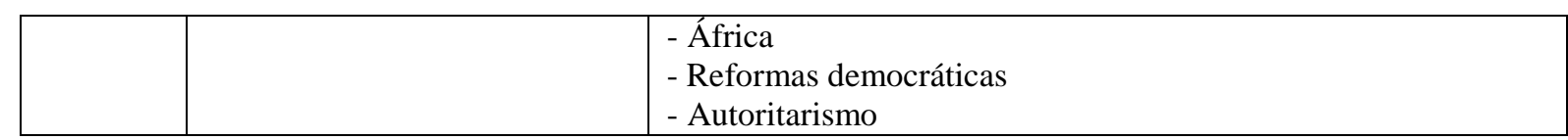

Fonte: Elaborado pelos autores (2020)

Os clusters abordaram as quatro nomenclaturas que podem refletir a relação democracia e meio ambiente. O termo Democracia Ambiental apareceu nos clusters 1 e 3 em um sentido comum ou próximo, ao entender a relação democracia e meio ambiente pelos valores ambientais como tecnologia de participação e fortalecimento dos atores no monitoramento e o exercício das tomadas de decisões nas gestões ambientais (Lawrence, Paudel, Barnes \& Malla, 2006, Tadaki, Sinner \& Chan, 2017).

O cluster 2 propõe um modelo teórico radical para democracia ecológica, defendendo a descentralização, a participação local no poder decisório e a instituição da economia localizada, que muito se aproxima da economia solidária e a comparação da Democracia Ecológica Radical com outros modelos teóricos de outros continentes (Kothari, 2009, 2014ab, Demaria \& Acosta, 2014).

A Democracia Ecológica foi empregada nos clusters 4, 5 e 8 também como formas participativas não institucionalizadas, pelos movimentos sociais, ativismo ambiental e justiça ambiental (Armiero \& D'Alisa, 2012, Dryzek, 1995, Dryzek \& Stevenson, 2011). No cluster 8 ao entender os movimentos do ecofeminismo como um caminho para democracia ecológica, por entender que os problemas ambientais são oriundos das (in)justiças ambientais promovidos pela sociedade patriarcal (Gaard, 2001).

É possível perceber que os termos Democracia Verde e Democracia Ecológica são frequentemente associados, e por vezes diferenciados em estudos de pesquisados, como é apresentado no cluster 5 em Dryzek (1995) sobre seus estudos da relação processos democráticos e resultados verdes, em que a democracia verde envolve a busca por formas políticas progressivamente menos antropocêntricas.

O cluster 5 serviu de base de referenciação para o cluster 6 de Arias-Maldonado (2000, 2007), que também aborda o termo Democracia Verde a partir da teoria da política verde e da democracia deliberativa, de modo que o termo estaria associado ao processo de comunicação, partidos políticos verdes e da racionalidade comunicativa (Arias-Maldonado, 2000, 2007).

Por fim, o termo Democracia Sustentável é utilizado nos clusters 7 e 9 no sentido político-eleitoral e partidarismo. Os autores, que são oriundos do continente africano, apresentam o termo no sentido do pluralismo político e na dificuldade do estabelecimento de 
uma democracia liberal nos países africanos frente à história de autoritarismo e do Estado monopartidário. Para esses clusters a democracia sustentável seria um estágio para se atingir a estabilidade democrática (Hauser, 1999; Burnell, 2001).

\section{Considerações Finais}

O artigo teve como objetivo realizar um estudo bibliométrico da produção científica que trata da relação entre meio ambiente e democracia publicada durante o período de 1944 a 2019, utilizando como termos de busca, environmental democracy, ecological democracy, green democracy ou sustainable democracy, resultando na análise de 118 artigos da base Scopus.

Nos aspectos quantitativos da produção científica sobre meio ambiente e democracia foi possível constatar que o crescimento no número de produções ocorreu a partir de 2014 e que os Estados Unidos, Reino Unido e Austrália são os países com maiores números de produções. Entretanto, essa publicação apresenta-se dispersa tanto do ponto de vista dos periódicos publicados, uma vez que se apresentam em mais de 95 periódicos de diversas áreas do conhecimento, quanto aos próprios países que mais publicam, pois as instituições de pesquisas de afiliação dos autores também apresentam-se dispersas dentro desses países.

Em relação aos nove clusters identificados, são compostos por poucos autores e reduzido número de trabalhos. Tais clusters trabalham de forma isolada sem vinculações entre si, o que poderia estar contribuindo negativamente para o avanço da literatura que ainda se apresenta em seus estágios iniciais considerando a quantidade crescente dos trabalhos se deu entre a partir do ano de 2014.

Pode-se identificar que existe uma lacuna nas produções entre o período de 1944 a 1992 que talvez tenha ocorrido em função dos descritores selecionados, ou pelo nível de amadurecimento das questões ambientais e suas possíveis vinculações com os processos democráticos.

$\mathrm{Na}$ literatura foram encontradas as quatro denominações utilizadas nos termos de busca: Democracia Ambiental, Democracia Ecológica, Democracia Verde e Democracia Sustentável. Na produção dos 18 pesquisadores mais citados não há consenso em relação à conceptualização dos respectivos termos utilizados e, por vezes, não os conceitualizam.

Porém, cabe ressaltar que embora a participação seja o ponto comum em todos essas denominações, o tipo e a qualidade dessa participação ocorre por mecanismos diferenciados. Na Democracia Ambiental a ênfase dada é relativa a valores, ou seja, à construção mais 
subjetiva de incorporação desse conceito na cultura por meio da produção de conhecimento e o que Tadaki, Sinner \& Chan (2017) denominam de tecnologia de participação. A Democracia Ecológica tem sua ênfase discursiva nos grupos sociais que participam no embate sobre conflitos ambientais, desta forma, ecofeminismo, patriarcado, sexismo e racismo estão presentes. A Democracia Verde trata de aspectos relacionados à teoria política verde, partidos verdes, sustentabilidade normativa e à racionalidade comunicativa. A Democracia Sustentável tem seu debate centrado em assuntos relacionados à teoria política como governança, pluripartidarismo, espaço público, política externa e autoritarismo.

Ao se entender o dinamismo, fluidez e emergência de discussões sobre a temática meio ambiente e democracia, os estudos se deram não apenas em países desenvolvidos, mas também nos emergentes ou em desenvolvimento, destacando que a discussão sobre democracia e meio ambiente vai além dos regimes democráticos, pois como afirmado por Baquero (2008) há processos democráticos formais híbridos que podem tender a atitudes autoritárias protegidas pela pretensa legitimidade oferecida pelos processos eleitorais, ou seja, um conceito de democracia restrito ao voto e não necessariamente à participação. Dessa forma é compreensível que o eixo transversal encontrado tenha sido a participação.

No que tange às contribuições do presente estudo, estas apontam diferentes aspectos quantitativos e qualitativos da produção científica sobre meio ambiente e democracia, tais como: as redes de autorias e coautorias e suas inter-relações; os países, universidades e periódicos que trabalham o tema; os aspectos tratados pelos autores dentro dessa relação e suas diferentes denominações utilizadas, entre outras. Constituindo-se como um rico panorama de informações que poderá servir de base para discussões e reflexões, especialmente considerando as características multidimensionais e transversais inerentes à relação entre dois temas de amplo espectro, meio ambiente e democracia, podendo também ser fonte de orientação e de direcionamentos de futuras pesquisas.

Quanto às limitações, são as típicas de estudos bibliométricos, decorrem das escolhas metodológicas feitas, especialmente pelo uso de uma única base e um único software, que embora não comprometam as contribuições do trabalho, poderão ser supridas em trabalhos futuros, pelo uso conjunto de bases de dados múltiplas e de outros softwares. Como pesquisas futuras, sugere-se aprofundar nas abordagens teóricas que oferecem suporte aos quatro termos, assim como identificar as áreas do conhecimento que tem mais estudado o tema democracia e meio ambiente. 


\section{Referências}

Abadia, L., \& Carvalho, M. (2018). Sustentabilidade na literatura de Gestão de Projetos: temas centrais, tendências e lacunas. Revista Gestão da Produção Operações e Sistemas, 13(4), 52. doi:https://doi.org/10.15675/gepros.v13i4.1971

Acselrad, H.et al.(2012). Desigualdade ambiental e acumulação por espoliação: o que está em jogo na questão ambiental?. Coletivo Brasileiro de Pesquisadores da Desigualdade Ambiental. e-cadernos CES, n. 17.DOI: https://doi.org/10.4000/eces.1138

Acselrad, H. (2010). Ambientalização das lutas sociais - o caso do movimento por justiça ambiental. Estudos Avançados, 24(68), 103-119. https://doi.org/10.1590/S010340142010000100010

Arias-Maldonado, M. (2000). The democratisation of sustainability: The search for a green democratic model. Environmental Politics, 9 (4), pp. 43-58.

Arias-Maldonado, M. (2007). An imaginary solution? the green defence of deliberative democracy. Environmental Values, 16(2), 233-252, doi:10.3197/096327107780474573

Armiero, M., \& D'Alisa, G. (2012). Rights of resistance: The garbage struggles for environmental justice in campania, Italy. Capitalism, Nature, Socialism, 23(4), 52-68. doi:10.1080/10455752.2012.724200

Baquero, M. (2008). Democracia formal, cultura política informal e capital social no Brasil. Opinão Publica, Campinas, v. 14, n. 2, p. 380-413. https://doi.org/10.1590/S010462762008000200005 .

Bangura, Y. (1992). Authoritarian rule and democracy in Africa: a theoretical discourse Authoritarianism, democracy, and adjustment, UNRISD (ISSN: 1012-6511), pp. 39-82.

Barros-Platiau, A. F.; Varella, M. D.; \& Schleicher, R. T. (2004). Meio ambiente e relações internacionais: perspectivas teóricas, respostas institucionais e novas dimensões de 
Research, Society and Development, v. 9, n. 7, e364974311, 2020

(CC BY 4.0) | ISSN 2525-3409 | DOI: http://dx.doi.org/10.33448/rsd-v9i7.4311

debate. Revista Brasileira de Política Internacional,47(2), 100 130. https://doi.org/10.1590/S0034-73292004000200004

Burnell, P. (2001). The party system and party politics in zambia: Continuities past, present and future. African Affairs, 100(399), 239-263. doi:10.1093/afraf/100.399.239

Bursztyn, M. A., \& Bursztyn, M. (2013). Fundamentos de política e gestão ambiental: caminhos para a sustentabilidade. Rio de Janeiro: Garamond.

Caro, M.; Romero, E.; Espinosa, M.; \& Guerrero, C. (2020). Evaluando contribuciones de usabilidad en soluciones TIC-IOT para la agricultura: Una perspectiva desde la bibliometría. Revista Ibérica de Sistemas e Tecnologias de Informação, Apr 2020, Issue E28, pp.681-692.

Carty, V., \& Onyett, J. (2006). Protest, Cyberactivism and New Social Movements: The Reemergence of the Peace Movement Post 9/11. Social Movement Studies, 5(3), 229-249. doi:10.1080/14742830600991586

Culkin, M. L. (1944). Green Democracy. Educational Forum. Volume 8, Issue 3, Pages 299308. doi:10.1080/00131724409340965.

Dryzek, J. S. (1995). Political and Ecological Communication. Environmental Politics. 4(4), pp. 13-30.

Dryzek, J. S., \& Stevenson, H. (2011). Global democracy and earth system governance. Ecological Economics. v.70(11), pp. 1865-1874.

Eckersley, R. (2019). Ecological democracy and the rise and decline of liberal democracy: Looking back, looking forward. Environmental Politics, p. 1-21. doi:10.1080/09644016.2019.1594536

Eckersley, R. (2006). From the liberal to the green democratic state: Upholding autonomy and sustainability. International Journal of Innovation and Sustainable Development, 1(4), 266283. doi:10.1504/IJISD.2006.013731 
Espinosa, M, Romero, E., Flórez, L., \& Guerrero, C. (2020). DANDELION: Propuesta metodológica para recopilación y análisis de información de artículos científicos. Un enfoque desde la bibliometría y la revisión sistemática de la literatura. Revista Ibérica de Sistemas e Tecnologias de Informação, Apr 2020, Issue E28, pp.110-122

Feil, A. A., \& Schreiber, D. (2017). Sustentabilidade e desenvolvimento sustentável: desvendando as sobreposições e alcances de seus significados. Cadernos EBAPE.BR, 15(3), 667-681. https://doi.org/10.1590/1679-395157473.

Gaard, G (2001). Women, water, energy: An ecofeminist approach. Organization and Environment, 14(2), 157-172. doi:10.1177/1086026601142002

Hauser, E. (1999). Ugandan relations with western donors in the 1990s: What impact on democratisation?. Journal of Modern African Studies, 37(4), 621-641. doi:10.1017/S0022278X9900316X

Kishi, K. (2020). Por que o Fator de Impacto é criticado?. Galoá Journal. Disponível em: https://galoa.com.br/blog/por-que-o-fator-de-impacto-e-criticado. Acesso em 26 abr. 2020.

Kothari, A. (2009). Radical ecological democracy: Escaping India's globalization trap.Development, 52 (3), pp. 401-409.

Kothari, A. (2014a). India 2100: Towards Radical Ecological Democracy (2014) Futures, 56, pp. 62-72.

Kothari, A. (2014b). Radical Ecological Democracy: A path forward for India and beyond.Development (Basingstoke), 57 (1), pp. 36-45.

Kothari, A., Demaria, F., \& Acosta, A. (2014). Buen Vivir, Degrowth and Ecological Swaraj: Alternatives to sustainable development and the Green Economy.Development (Basingstoke), 57 (3-4), pp. 362-375. 
Lawrence, A., Paudel, K., Barnes, R., \& Malla, Y. (2006). Adaptive value of participatory biodiversity monitoring in community forestry. Environmental Conservation, 33(4), 325-334. doi:10.1017/S0376892906003432

Marconi, M. A., \& Lakatos, E. M. (2017). Técnicas de pesquisa: planejamento e execução de pesquisa, amostragens e técnicas de pesquisa, elaboração, análise e interpretação de dados. 8 . ed. São Paulo, SP: Atlas.

Marques, L. (2018). Capitalismo e colapso ambiental. 3. ed. São Paulo: Unicamp.

Mattos, P. L. C. L. (2004). "Bibliometria": a metodologia acadêmica convencional em questão. RAE eletrônica, v. 3, n. 2, p. 280-306.

Medeiros Filho, A. R., \& Russo, S. L. (2018). Marcas como um indicador: revisão sistemática e análise bibliométrica da literatura. Biblios: Journal of Librarianship and Information Science. N.71, pp.-50-67. DOI 10.5195/biblios.2018.464.

Menteş, S. A. (2019). Online Environmental Activism: The Case of Iğneada Floodplain Forest.SAGE Open, 9(3), 215824401987787. doi:10.1177/2158244019877877.

Morais, L. A. (2017). Conselhos Ambientais: Uma análise do processo de participação de conselheiros municipais no Território Açu-Mossoró-RN. 2017. 204 f. Dissertação (Mestrado) - Curso de Pós-graduação em Ambiente, Tecnologia e Sociedade, Universidade Federal Rural do Semi-Árido, Mossoró.

Nascimento, E. P. (2012). Trajetória da sustentabilidade: do ambiental ao social, do social ao econômico. Estudos Avançados, 26(74), 51-64. https://doi.org/10.1590/S010340142012000100005.

Pickering, J., Bäckstrand, K., \& Schlosberg, D. (2020). Between environmental and ecological democracy: theory and practice at the democracyenvironmentnexus, Journal of Environmental Policy \& Planning, 22:1, 1-15, DOI:10.1080/1523908X.2020.1703276. 
Pott, C. M., \& Estrela, C. C. (2017). Histórico ambiental: desastres ambientais e o despertar de um novo pensamento. Estudos Avançados, 31(89), 271-283. https://doi.org/10.1590/s010340142017.31890021.

Queiroz, E. F. C. (2017). Ciberativismo: a nova ferramenta dos movimentos sociais. Revista Panorama, v. 7, n. 1, p. 2-5.

Severino, A. J. (2018). Metodologia do trabalho científico. São Paulo: Cortez.

Tadaki, M., Sinner, J., \& Chan, K. M. A. (2017). Making sense of environmental values: A typology of concepts. Ecology and Society, 22(1). doi:10.5751/ES-08999-220107.

Teixeira, M. L. M, Iwamoto, H. M., \& Medeiros, A. L. (2013). Estudos Bibliométricos (?) em Administração: discutindo a transposição de finalidade. Administração: Ensino e Pesquisa. Rio de Janeiro. 14 (3). p. 423-452. DOI: https://doi.org/10.13058/raep.2013.v14n3.57.

van Eck, N. J., \& Waltman, L. (2014). Visualizing bibliometric networks. In Y. Ding, R. Rousseau, \& D. Wolfram (Eds.), Measuring scholarly impact: methods and practice (pp. 285- 320). London: Springer.

Vanti, N. A. P. (2002). Da bibliometria à webometria: uma exploração conceitual dos mecanismos utilizados para medir o registro da informação e a difusão do conhecimento. Ciência da Informação, v. 31, n.2, p. 152-62.

\section{Porcentagem de contribuição de cada autor no manuscrito}

Lucas Andrade de Morais - 70\%

Lucia Santana de Freitas - 30\% 